\title{
A INSUFICIÊNCIA DE DIFERENCIAÇÃO FUNCIONAL OBSERVADA A PARTIR DA CRISE NO CENÁRIO BRASILEIRO
}

\author{
Matheus F. Nunes de Souza ${ }^{1}$ \\ Fernando Tonet $^{2}$
}

\author{
THE INSUFFICIENCY OF FUNCTIONAL \\ DIFFERENTIATION OBSERVED FROM THE CRISIS \\ ON THE BRAZILIAN SCENARIO
}

\begin{abstract}
RESUMO: O presente trabalho tem como objeto promover uma descrição dos sistemas sociais a partir do cenário brasileiro utilizando a teoria dos sistemas sociais de Niklas Luhmann. A fim de cumprir com tal proposta, o objetivo deste artigo é constatar se o sistema do Direito sofre interferências do ambiente externo que podem afetar seus processos decisórios. O problema de pesquisa proposto é identificar se existe uma insuficiência de diferenciação funcional do sistema do Direito no Brasil. A hipótese de pesquisa a ser testada refere que tal insuficiência existe e é ocasionada em virtude das constantes interferências por elementos políticos e econômicos. O método de pesquisa utilizado foi o hipotético dedutivo, e as técnicas de pesquisa utilizadas foram a de pesquisa bibliográfica, fichamentos, categorias e conceitos operacionais. As conclusões parciais indicam que a hipótese se mostra verdadeira, indicando que no Brasil não existe uma completa diferenciação funcional do sistema do Direito.
\end{abstract}

Palavras-chave: Teoria dos Sistemas Sociais. Diferenciação Funcional. Modernidade Periférica. Impeachment. Direito e Política.

\begin{abstract}
The present work aims to disseminate a version of social systems using Niklas Luhmann's theory of social systems. In order to comply with the proposal, the article contained in this article is as follows: The research problem is a fundamental issue of functional differentiation of the legal system in Brazil. The hypothesis of a tested research is one that exists and is occasioned in the advantages of interference by political and economic states. The research method used was the hypothetical deductive, and how the research techniques were included in the bibliographic research, diagrams, categories and operational concepts. The existences indicate that the research is truly presented, there is no functional differentiated function of the Law system.
\end{abstract}

Keywords: Social Systems Theory. Functional Differentiation. Peripherical Modernity. Impeachment. Law and Politics.

\footnotetext{
${ }^{1}$ Bacharel (2017) e Mestrando em Direito pela Faculdade Meridional - IMED, com Bolsa-auxílio CAPES/PROSUP (2017). Pesquisador no Grupo de Pesquisa Ética, Cidadania e Sustentabilidade. Pesquisador no Grupo de Estudos Modelos Constitucionais Sistêmicos na Pós-Modernidade, atuando nos seguintes temas: Sociologia do Direito, Teoria dos Sistemas Autopoiéticos, Sustentabilidade, Teoria Constitucional. Membro da Associação dos Advogados Criminalistas do Planalto Médio (AACPLAM). Advogado.

2 Doutorando em Direito pela Universidade do Vale do Rio dos Sinos - Unisinos. Estágio de doutoramento sanduíche na Universidad Diego Portales - Chile (2017). Mestre em Direito pela Universidade Regional Integrada do Alto Uruguai e das Missões - URI (2012). Especialista em Direito Penal e Processo Penal pela Faculdade Meridional - IMED (2011). Especialista em Direito Civil e Direito Processual Civil pelo Instituto de Desenvolvimento e Cultura - IDC (2010).
} 


\section{INTRODUÇÃO}

Através dos anos a sociedade foi se modificando, o nível de interações e fluxo de informações a nível global aumentaram, principalmente após a queda do muro de Berlim, na década de 1990, marco histórico este que botou fim à União das Repúblicas Socialistas Soviéticas (URSS) e à dicotomia mundial vivida durante a Guerra Fria.

Esse evento histórico desencadeou um processo de integração global, visivelmente percebido nos mercados e na economia. Ainda, com a predominância do capitalismo, o surgimento de novas tecnologias e aprimoramento de outras, a comunicação tornou-se algo, de fato, global.

Ocorre que com esse processo de globalização das informações verifica-se uma rápida reprodução comunicativa no meio social, o que também é influenciado pelas interações em níveis múltiplos (intraestatal, interestatal, supranacional e internacional). Todos esses fatores advindos do intenso e incessante processo de globalização fazem com que a complexidade social aumente continuamente, atingindo níveis imprevisíveis de possibilidades nas mais diversas situações fáticas.

Em virtude disso, optou-se por utilizar o modelo pragmático-sistêmico a fim de observar e descrever os fenômenos sociais, pois mostra-se um modelo apto a lidar com a complexidade da sociedade e cada um dos demais subsistemas, especialmente o Direito, a Política e a Economia.

Este artigo toma por objeto e limita-se a promover uma descrição do funcionamento dos sistemas sociais no Brasil, iniciando no cenário da crise política que permeou o país em meados de 2015, culminando com o impeachment da ex-presidente Dilma Rousseff, bem como do último evento impactante no mundo da Política, que foi a primeira denúncia contra o então presidente Michel Temer, pela suposta prática de atos de corrupção.

Partindo disso, o objetivo deste trabalho é verificar se o sistema do Direito sofre interferências de elementos ambientais, em especial da Política e da Economia, que possam vir a influenciar seus processos decisórios, justificando assim as decisões tão 
destoantes que ocorreram nos casos da ex-presidente Dilma e do atual presidente, embora ambos sob graves acusações.

Para que se possa cumprir com tal objetivo, o problema de pesquisa proposto é o seguinte: existe uma insuficiência de diferenciação funcional no sistema do Direito no Brasil? A fim de responder tal pergunta utilizou-se o método de pesquisa hipotético dedutivo, aliado às técnicas de pesquisa bibliográfica, fichamentos, categorias e conceitos operacionais.

Este trabalho parte da hipótese de que sim, existe uma insuficiência de diferenciação funcional do Direito no Brasil, e ela ocorre em virtude das constantes interferências de elementos políticos e econômicos, principalmente por conta de meios simbolicamente generalizados, tais como o poder e o dinheiro.

Para confirmar a hipótese de pesquisa, a primeira parte do texto serve como breve noção introdutória à Teoria dos Sistemas Sociais, de Niklas Luhmann, a fim de que o leitor fique familiarizado com a terminologia própria da teoria sistêmica.

Em um segundo momento, busca-se explicar como acontece a divisão centro/periferia dentro do Sistema da Sociedade, justificando, de acordo com o pensamento de Marcelo Neves, porque o Brasil é considerado um país de "Modernidade Periférica", e por consequência, fundamentando a possibilidade de existência de uma insuficiência de diferenciação funcional do sistema do Direito.

Por último, será analisado o cenário do impeachment da ex-presidente Dilma Rousseff e a decisão tomada pelos congressistas e então comparar-se-á com a atmosfera da denúncia contra o presidente Michel Temer e seu desfecho, buscando explicar porque houveram decisões diametralmente opostas em ambos os casos.

\section{BREVES CONSIDERAÇÕES SOBRE A TEORIA DOS SISTEMAS SOCIAIS}

Ao observar a história da sociologia, no começo do século passado (e em particular na Alemanha, após a Segunda Grande Guerra), sua identidade foi desenvolvida escondendo suas relações com a sociedade. Visivelmente buscava teorizar sobre entidades sociais, com categorias tais como papéis, interação, intenção e ação social. Tal formação 
estrutural da sociologia levava a caminhos semelhantes aos das ciências naturais (BECHMANN; STEHR, 2001, p. 187).

Niklas Luhmann, fortemente influenciado pelo pensamento estruturalista de Parsons, toma como objeto de estudo a sociedade moderna e, em 1968, começa seus estudos para desenvolvimento de uma teoria da sociedade. A mensagem que Luhmann busca transmitir é a seguinte: ou a sociologia é uma teoria da sociedade, ou não é uma ciência (BECHMANN; STEHR, 2001, p. 186-187).

O que Luhmann busca explicar é que sua teoria da Sociedade busca reivindicar a universalidade da apreensão do objeto, ou seja, como Teoria Sociológica, ela busca tratar de tudo que é social, e não apenas de fragmentos (LUHMANN, 2016a, p. 11).

Porém, para a elaboração de uma Teoria da Sociedade ancorada em uma diferenciação entre sistema e ambiente, Luhmann não poderia utilizar os mesmos conceitos que advinham da sociologia clássica, pois esta era carregada de demasiada ontologia (LUHMANN, 2006, p. VIII). A proposta de Sociedade do sociólogo alemão é radicalmente anti-humanista ${ }^{3}$, não ontológica e construtivista radical (BECHMANN; STEHR, 2001, p. 189).

O que acontece é a transferência da estrutura de operação autorreferencial do sujeito à sua teoria dos sistemas sociais, o que provoca uma mudança radical (digna de uma virada paradigmática) nas posições epistemológicas baseadas na dicotomia sujeitoobjeto, dando uma visão anti-humanista, não ontológica e construtivista radical de sua teoria (BECHMANN; STEHR, 2001, p. 188-189).

O modelo pragmático-sistêmico apresenta-se como uma das melhores formas de compreensão da sociedade (pós-)moderna, tendo em vista que busca não apenas preservar a complexidade da Sociedade em si ou dos fenômenos que ocorrem no seu espaço, mas busca compreender e descrever as problemáticas que surgem no âmbito social, lidando com a complexidade de cada um destes fenômenos.

\footnotetext{
${ }^{3}$ Este é um dos temas mais acalorados quando se debate a questão do homem e a teoria dos sistemas autopoiéticos. No entanto, esta visão antropocêntrico-iluminista, ainda muito presente, é denominada por Luhmann de velho pensamento europeu. O sociólogo propõe um quarto insulto à vaidade humana que provém do fato de que não é possível guiar a sociedade, quer por instituições políticas, quer pela racionalidade humana (SCHWARTZ, 2014, p. 112).
} 
Tendo em vista que a sociedade (pós-)moderna é policontextural, ou seja, permite não apenas a pluralidade de autodescrições, mas também a pluralidade de centros de produção normativa, a teoria da sociedade enfrenta a tarefa de elevar seu próprio potencial de complexidade: interpretar os feitos mais heterogêneos com os mesmos conceitos, e então garantir a possibilidade de comparação com os mais diversos contextos relacionados (LUHMANN, 2006, p. 26).

Essa pluralidade de contextos é resultado do pressuposto de que o mundo ${ }^{4}$ é expresso por uma rede de distinções e rótulos contingentes que sempre devem ser entendidas dentro de um contexto. Assim sendo, um sistema não surge a partir de si próprio, organizando sua própria estrutura e operações, ou seja, não se trata de uma identidade entre identidade e diferença (a identidade de um sistema), mas sim de uma diferença entre identidade e diferença (LUHMANN, 2016a, p. 26).

Quer dizer, um sistema só se reconhece como sistema pois tem a capacidade de se distinguir ${ }^{5}$ do entorno (ambiente) - e isso é possível graças à sua autorreferencialidade. Tratando-se de uma teoria pós-ontológica, é possível perceber que séries de eventos de diferenciação tomam o lugar de séries de eventos da intelecção (CLAM, 2007).

A partir da capacidade de distinção das unidades heterogêneas surgem plexos estruturados que buscam reduzir a complexidade, cada qual operando em seus limites, com suas próprias operações. É possível observar quatro grandes sistemas no mundo: (1) máquinas; (2) sistemas orgânicos; (3) sistemas sociais e; (4) sistemas psíquicos (LUHMANN, 2016a, p. 17).

No caso das máquinas, se tratam de sistemas sem vida que não conseguem reproduzir a si mesmos. Os sistemas orgânicos são orientados por operações que são

\footnotetext{
${ }^{4} \mathrm{O}$ mundo, segundo a terminologia de George Spencer-Brown, pode ser concebido como um espaço indeterminado que é dividido em dois por meio de uma distinção, graças a qual é possível distinguir um lado interno e outro externo. Quando se parte do ponto de vista do sistema, o mundo é a unidade da diferença entre sistema e entorno. Assim sendo, qualquer observador pode atuar apenas em um mundo, o qual marca distinções (CORSI; ESPOSITO; BARALDI, 1996, p. 115).

${ }^{5}$ Esta é uma influência de um sistema lógico-matemático teorizado por George Spencer-Brown na obra Laws of Form. Este sistema possui uma só lei, que é a de "fazer uma distinção", e apenas uma operação: distinção. Distinções podem ser aplicadas a distinções; distinções podem ser distintas de outras distinções, possibilitando, assim, que sejam feitas várias operações, porém, sempre vai se tratar de uma operação de distinção. Assim sendo, uma Forma sempre vai ser a unidade de uma distinção (DIREITO UFPR, 2014).
} 
processos fisiológicos. Quando se tratam de sistemas psíquicos, as operações são os pensamentos. E no caso dos sistemas sociais, as operações são comunicações.

Luhmann dedica-se ao estudo dos sistemas sociais, que nada mais é que a Sociedade e seus subsistemas. O sociólogo descreve a Sociedade como um sistema autopoiético. Segundo sua teoria, a sociedade moderna é caracterizada pela autonomia funcional e a clausura operativa, bem como pela capacidade de se auto-organizar e de se auto-reproduzir.

Os sistemas sociais são sistemas que possuem como unidade básica a comunicação, isso quer dizer que a sociedade é comunicação e tudo que se comunica ou faz parte da sociedade, ou é sociedade (ROCHA; SCHWARTZ; CLAM, 2013, p. 63). Assim, a Sociedade é o sistema global de comunicação.

No entanto, dentro da sociedade existem os mais variados tipos de comunicação: social, jurídica, econômica, política, moral, religiosa, dentre outras. Para que seja possível lidar com a complexidade das comunicações existentes no sistema social, a sociedade executa operações em sucessão para diferenciar cada tipo de comunicação. Essas operações de diferenciação que surgem dentro da Sociedade é que darão origem aos subsistemas, cada um com um tipo de comunicação específica.

É preciso dizer que tanto o Sistema Social como seus subsistemas são diferenciados funcionalmente, bem como operam dentro de seus próprios limites e a partir de seus próprios elementos - ideia de autopoiese que foi transposta por Luhmann da Biologia.

Como um sistema organizado, o sistema autopoiético é uma rede de processos de produção (transformação e destruição) de componentes que produzem os componentes que: (i) por meio de sua interação e transformação continuamente regenera e realiza uma rede de processos (relações) que os produzem, e: (ii) o constitui como uma unidade concreta no espaço em que os componentes existem, especificando o domínio topológico de sua realização como uma rede (MATURANA; VARELA, 1980, p. 78-79)

Muito embora um sistema autopoiético opere apenas dentro de seus limites (clausura operativa), ou seja, se reproduz com base e a partir de seus próprios elementos, não quer dizer que ele não tenha nenhum tipo de contato com o ambiente, sem poder ser influenciado por este. 
Como consequência da complexidade e autorreferencialidade, bem como da coevolução que sistemas sociais tiveram junto com sistemas psíquicos (pessoas), ambos os sistemas foram conduzidos a uma aquisição conjunta, que é utilizada por estes dois sistemas. Além disso, essa aquisição evolutiva fez com que os dois dependessem dela, se tornando obrigatória, imprescindível e imperiosa de suas complexidade e autorreferencialidade. Essa aquisição evolutiva que impede que os sistemas não sejam destruídos pela complexidade do ambiente é denominada de "Sentido" (LUHMANN, 2016a, p. 80).

É possível dizer, também, que o Sentido é o meio responsável pelo qual um sistema consegue trazer para si, aproximar, a complexidade existente do seu entorno. Assim sendo, o sentido não é uma consequência da ação, mas sim uma forma de distinguir o sistema do entorno (ROCHA; SCHWARTZ; CLAM, 2013, p. 64).

O Sentido é responsável por controlar e delimitar os limites do sistema. O sistema funcionalmente diferenciado, com capacidade de distinguir, estabelece suas estruturas, diminuindo sua complexidade face o ambiente. No caso do ambiente, que é tudo aquilo que não é sistema, não é possível qualquer tipo de controle de complexidade. Assim sendo, é a partir do Sentido que é possível diferenciar Ego de Alter - a distinção sistema/entorno (seja essa distinção externa, seja ela interna)

Então, com o passar do tempo e o aumento das comunicações, a complexidade do sistema aumenta, e, consequentemente, a complexidade do ambiente. Para que o sistema evolua e acompanhe este aumento da complexidade, primeiramente ele sofre uma variação de um elemento autopoietico, respectivo aos padrões de reprodução vigentes até o momento. Então, passa à seleção da estrutura, que torna possível que a respectiva variação se constitua em condição das seguintes reproduções. Por último, ocorre a estabilização do sistema para mantê-lo dinamicamente estável para que seja possível a reprodução autopoietica da forma, que experimentou a mudança (LUHMANN, 2016b, p. 323).

Nas últimas décadas muitos pressupostos tradicionais foram redefinidos frente à complexidade social, à globalização e ao pluralismo de culturas em um mesmo espaço geográfico. Exemplo dessas reformulações foi quando Canotilho (2012, p. 31) afirmou que 
o Dirigismo Constitucional estava morto, e que a Constituição não passava de uma "bíblia de promessas".

Assim sendo, frente ao cenário contemporâneo de interações desde o nível local até o global, é necessária a utilização de um modelo teórico apto a enfrentar os anseios sociais e a complexidade dos eventos de diferenciação, razão pela qual adotou-se o referencial luhmanniano.

\section{3 “MODERNIDADE PERIFÉRICA”: INSUFICIÊNCIA DE DIFERENCIAÇÃO FUNCIONAL?}

Considerando a autopoiese do direito como sistema social, é necessário discutir que esta ideia não encontra plausibilidade empírica na maioria dos países da sociedade mundial atual. Na chamada condição de "modernidade periférica", quando das circunstâncias sociais e legais de reprodução, verifica-se uma verdadeira mescla de códigos e critérios de comunicação que são impostas em todas as dimensões da vida social.

Conforme aumenta a complexidade social, existe uma reestruturação para a formação de sistemas parciais funcionalmente específicos, o que leva a uma produção em grande quantidade de possibilidades de experimentação e ação (LUHMANN, 1983, p. 175). No caso do Direito, pode ser interpretado como a diferença a partir do código legal/ilegal, pois nenhum outro sistema opera sob este código (LUHMANN, 1989, p. 64).

O código-diferença legal/ilegal é implicado através da positivação do Direito, fazendo com que o sistema jurídico adquira, assim, sua clausura operativa. Dessa forma, a positivação pode ser concebida como autodeterminação operativa do Direito (NEVES, 1996a, p. 408). Já esta autodeterminação se fundamenta entre a distinção entre expectativas normativas e cognitivas (LUHMANN, 1983, p. 175). Partindo da diferença entre o normativo e o cognitivo é que se garante a clausura operativa e a abertura ao meio (NEVES, 1996a, p. 409) - assim o Direito é um sistema operativamente fechado, mas cognitivamente aberto.

Porém, a teoria dos sistemas não vira as costas para os problemas que surgem ao redor do globo, que são consequências de um desenvolvimento assimétrico dessa sociedade, fazendo, dessa forma, com que surja uma diferenciação segmentária secundária em Estados e, também como, organizações territoriais delimitadas de forma 
estritas, que são válidas tanto para o sistema político quanto para o jurídico. Essa própria diferenciação secundária é fruto da diferenciação funcional da sociedade moderna, mas acaba levando a certa segmentação regional do sistema político em termos de Estados, ao passo que motivos econômicos forçam uma diferenciação de acordo com centro e periferia, ou seja, conforme regiões altamente desenvolvidas ou subdesenvolvidas (LUHMANN, 1989, p. 85). Quando ocorre uma assimetrização externa ao nível da orientação normativa, pode surgir uma negação da autorreferência operacional do Direito (NEVES, 1994, p. 125). É a chamada insuficiência de diferenciação funcional.

A insuficiência de diferenciação funcional leva à reprodução por elementos diferentes do sistema especializado, danificando diretamente a autorreferência de base, a reflexividade e a reflexão como fases que constituem a reprodução operacionalmente fechada do sistema jurídico. Dependendo do grau de severidade que esta mutação acomete o sistema, pode fazer com que este perca sua autorreferência elementar, não mais diferenciando operações a partir de seu código-diferença, podendo levar até mesmo ao desaparecimento das fronteiras sistêmicas (NEVES, 1994, p. 129).

Esse é o mesmo entendimento que tem Luhmann. Também fazendo referência à Neves, o sociólogo alemão explica que um sistema jurídico que acaba exposto a interferências num amplo espectro de questões, acaba por operar em um estado de corrupção (LUHMANN, 2016b, p. 109).

O exemplo mais visível de sobreposição de um código binário sobre o outro pode ser observada nas relações entre Direito e Política, acoplados estruturalmente através da Constituição. Em casos de Constituições Simbólicas, a esfera política avança em detrimento do código que realiza a diferença entre legal e ilegal (NEVES, 1994, p. 130).

Com a evolução social e a emergente complexidade, o desenvolvimento da sociedade moderna restou bifurcado, pois determinadas regiões (estatalmente delimitadas) não conseguiram efetivar de forma adequada a autonomia sistêmica a partir de uma completa diferenciação funcional. Isso fez com que os sistemas sociais surgidos nos países periféricos não conseguissem estruturar ou determinar de forma adequada a crescente e rápida complexificação social (NEVES, 1994, p. 148-149). 
As limitações autorreferenciais dos sistemas político e jurídico compreendem a principal causa dos fatores negativos da realização do Estado democrático de direito em países em condição de modernidade periférica. Nestes territórios segmentados não haveria efetivação da autonomia sistêmica através da diferenciação funcional, nem da realização da cidadania como instituição de inclusão social (NEVES, 2015, p. 121).

Os códigos binários ter/não ter e poder/não poder acabam se sobrepondo ao código diferença do sistema jurídico (legal/ilegal), o que pode levar a situações extremas, tais como a promoção de "privilégios" de uns sobre outros, ou a promoção de "exclusões" de pessoas ou grupos de ter acesso ao subsistema social do direito. Isso leva a relações de "sub-integração" e "sobreintegração" entre os sistemas (NEVES, 1994, p. 150).

A subintegração leva a uma dependência dos critérios sistêmicos sem um pleno acesso às devidas prestações (NEVES, 2005, p. 68), enquanto a sobre-integração é responsável por permitir benefícios do sistema sem dependência dos seus critérios e regras (NEVES, 1994, p. 150). Enquanto aquela está relacionada às massas, esta relacionase com grupos privilegiados que, com suporte da burocracia estatal, bloqueiam as ações de reprodução do direito (NEVES, 2005, p. 68).

Este estado operacional de corrupção leva à danificação da Constituição enquanto acoplamento estrutural de dois sistemas autônomos através de bloqueios generalizados à reprodução do sistema jurídico e político (NEVES, 2015, p. 120), o que acarreta, por consequência, em um bloqueio da concretização normativa-jurídica do texto constitucional, de forma generalizada e permanente, por intromissões da política, da economia, da moral, das relações familiares (NEVES, 1996b, p. 323).

Assim sendo, os principais obstáculos à efetivação do Estado Democrático de Direito em países periféricos se encontram no plano constitucional (NEVES, 2015, p. 128), pois com a Constituição minada em virtude de corrupção sistêmica (por injunções econômicas, políticas, morais, entre outras), percebe-se um fenômeno de Constitucionalização Simbólica em sentido negativo, que se traduz no fato de que o texto constitucional é insuficientemente concretizado normativo-juridicamente de forma generalizada (NEVES, 1994, p. 83). 
Portanto, a condição de modernidade periférica mantém estritas relações com as diferenças regionais de desenvolvimento econômico, além de outros fatores, onde os sistemas sociais não conseguem se desenvolver completamente, encontrando dificuldades estruturais para lidar com a hipercomplexidade social.

Dessa forma, o sistema jurídico começa a sofrer com insuficiência de diferenciação funcional em virtude de intromissões (principalmente) de critérios e programas políticos e econômicos, levando-se a reproduzir de forma não-circular. É por causa de uma reprodução sistêmica jurídica baseada em padrões externos ao direito que verifica-se um estado de corrupção, constatado empiricamente em situações onde o texto constitucional não é condizente com a realidade constitucional (não é concretizado), em razão dos bloqueios generalizados à Constituição.

\section{A INSUFICIÊNCIA DE DIFERENCIAÇÃO FUNCIONAL OBSERVADA A PARTIR DO IMPEACHMENT DA EX-PRESIDENTE DILMA ROUSSEFF E A DENÚNCIA POR CORRUPÇÃO CONTRA O PRESIDENTE MICHEL TEMER}

Conforme explicado anteriormente, o estado de corrupção de um sistema ocorre em virtude de uma insuficiência de diferenciação funcional, fazendo com que o sistema jurídico passe a operar com critérios, programas e códigos a partir do entorno. Isso teria maior facilidade de ocorrer em países em condição de "modernidade periférica".

Esta parte do trabalho visa analisar dois momentos distintos pelo qual o Brasil passou: primeiramente, os ares que antecederam o processo de impedimento, os principais momentos do processo de impeachment da ex-presidente do Brasil, Dilma Rousseff e suas implicações políticas; e, num segundo momento, analisar o panorama que o ex-vice-presidente assume o cargo da presidência, bem como analisar a denúncia por corrupção que Michel Temer foi alvo, sua votação e o resultado.

Brevemente, o processo de impedimento de um presidente da República desenrolase em seis fases: (i) o pedido, (ii) a aceitação, (iii) a primeira votação (na Câmara dos Deputados), (iv) envio para o Senado Federal, (v) a segunda votação (no Senado), e por fim, (vi) o julgamento e sentença (BRASIL, 1950). 
(i) O início se dá através de uma denúncia que pode ser apresentada por qualquer cidadão que goze de seus direitos políticos à Câmara dos Deputados, munido de provas fáticas do cometimento de Crime de Responsabilidade por parte do Presidente da República, em conformidade com o disposto na Lei 1.079/1950 e com o artigo 85, da Constituição Federal da República Federativa do Brasil;

(ii) Após isso, o presidente da Câmara dos Deputados analisará a existência de procedência da denúncia ou determinará o arquivamento. Em caso de aceitação da denúncia, o presidente da Câmara determinará o envio aos demais deputados federais. Ao receberem o pedido, os deputados formam uma Comissão para julgá-lo em dez sessões. Nesta parte, o (a) Presidente da República pode apresentar sua defesa;

(iii) Ocorre então a primeira votação, na Câmara dos Deputados, onde os congressistas deverão dar prosseguimento ou não ao processo. Para que ocorra o prosseguimento, é necessário aprovação por 2/3 (dois terços) dos membros da casa;

(iv) Então, o processo é enviado ao Senado Federal, onde será formada outra Comissão de Julgamento, que também emitirá um parecer sobre o processo. Após a instauração do processo no Senado Federal, o (a) Presidente da República ficará afastado por até 180 (cento e oitenta) dias. Se decorrido esse prazo o julgamento não for concluído, cessará o afastamento sem o prejuízo do prosseguimento do processo;

(v) Nesta fase ocorre a votação no Senado Federal, em sessão que é presidida pelo presidente da Corte Constitucional Brasileira (Supremo Tribunal Federal - STF). Os senadores são chamados a dar seu voto e então se 2/3 (dois terços) dos membros do Senado forem favoráveis ao Impeachment, ocorre o efetivo impedimento, onde o (a) Presidente torna-se inelegível pelo período de oito anos, assumindo então o VicePresidente da República em exercício.

(vi) Por último, é lavrada a sentença condenatória do chefe do Poder Executivo.

\subsection{O Impedimento da ex-presidente Dilma Rousseff}

Em outubro de 2014 o Brasil teve uma das eleições presidenciais mais acirradas desde sua redemocratização no final da década de 1980. A (ex) presidente Dilma Rousseff 
foi reeleita no segundo turno de votação, com 51,64\% dos votos válidos (54.501.118 votos).

Um ano após a eleição, a ex-presidente Dilma enfrentou uma grave crise política, uma grave recessão econômica, forte oposição no Congresso Nacional e uma taxa de aprovação popular extremamente baixa. Em virtude disso, o Governo anunciou corte de gastos, aumento de impostos e reduções na Administração Pública, visando se recuperar da crise. Ainda, um grande escândalo de corrupção na Empresa Pública Petrobrás eclodiu, agravando ainda mais a crise no Governo.

A ex-presidente Dilma foi denunciada perante a Câmara dos Deputados pelo cometimento de crime de responsabilidade, por violações à Lei de Responsabilidade Fiscal, pela não contabilização de empréstimos tomados de Instituições Financeiras Públicas, contrariando a proibição de fazer os referidos empréstimos e o dever de transparência quanto à situação financeira do país - resultando em maquiagem deliberada das contas públicas (BICUDO; PASCHOAL, 2015).

Segundo explicam os denunciantes, os contornos do crime de responsabilidade se dariam, pois o ex-presidente Luís Inácio Lula da Silva é quem estaria "governando" o Brasil, pois a figura do ex-presidente Lula seria indissociável à da ex-presidente Dilma.

Ademais, a ex-presidente Dilma teria ciência de operações escusas que estariam sendo promovidas sobre as diretrizes financeiras do país, mais um motivo pelo qual ensejaria a instauração do processo de impedimento.

As violações jurídicas ocorridas seriam em virtude de atos violadores das finanças públicas relativas a mandato anterior (01/01/2011-01/01/2015), que então constituiriam crime de responsabilidade, incorrendo nos crimes do artigo 85, V, VI e VII, da Constituição Federal do Brasil; nos artigos 4으, V e VI; 9으, 3 e 7; 10, 6,7,8 e 9; e 11, 3, da Lei 1.079/1950.

No mesmo sentido, o Conselho Federal da Ordem dos Advogados do Brasil também apresentou pedido de impedimento contra a ex-presidente da República, embora com menor extensão à denúncia anteriormente apresentada, mas com conteúdo extremamente semelhante ao documento já em tramitação.

Assim sendo, a denúncia foi recebida pelo então presidente da Câmara, o exDeputado Federal Eduardo Cunha, que encaminhou aos demais parlamentares cópia da 
denúncia. Logo, houve a formação da Comissão Parlamentar responsável por avaliar a acusação e emitiram parecer favorável (BRASIL, 2015) ao prosseguimento da denúncia, afirmando que haveria indícios mínimos do cometimento de crime de responsabilidade pela ex-presidente da República.

Então, houve a votação na Câmara dos Deputados pela admissibilidade do parecer apresentado pela Comissão, indicando o cometimento dos crimes de abertura de créditos suplementares sem autorização do Congresso Nacional (artigo 85, VI e artigo 167, V; Lei 1.079/1950, artigo 10, 4; artigo 11, 2) e contratação ilegal de operações de crédito (Lei 1.079/1950, artigo 11, 3), onde 367 parlamentares votaram favoravelmente e 167 contrários, sendo o processo encaminhado ao Senado Federal.

Nesse sentido, foi instaurada Comissão Especial de Impeachment no Senado Federal, a fim de investigar a denúncia e o parecer anteriormente apresentado, onde concluiu-se que a Chefe do Poder Executivo teria agido com irresponsabilidade na execução da política fiscal brasileira, sendo claros os indícios de autoria e materialidade dos delitos de responsabilidade presidencial, sendo emitido parecer (BRASIL, 2016a) favorável ao impedimento do representante máximo da República.

Assim sendo, deu-se início à fase de instrução e julgamento do processo, sendo aberto o prazo para a denunciada apresentar sua resposta à acusação (BRASIL, 2016b). Em sua defesa preliminar, a defesa da ex-presidente da República alegou, sinteticamente, em fase preliminar, que o processo deveria ser declarado nulo, tendo em vista o desvio de poder; e em questões de mérito, a absolvição sumária da ex-presidente, tendo em vista que não cometeu nenhum dos ilícitos imputados.

Em sede de alegações finais, a acusação (BRASIL, 2016c), verificada na figura dos denunciantes, alega que o cometimento dos crimes são claros, pois uma vez não contabilizados os valores tomados dos bancos públicos, houve sério comprometimento do cálculo da meta de superávit primário, constatando que a meta vigente havia sido fraudada.

No que tange às alegações finais da defesa (BRASIL, 2016d), requereu-se a absolvição sumária da ex-presidente da República, em virtude de ausência de materialidade dos fatos criminosos, de acordo com análise das provas. 
Após esta fase, a ex-presidente da República foi pronunciada e então levada à julgamento pelos parlamentares do Senado Federal, onde, pelo placar de 61 (sessenta e um) votos favoráveis à cassação do mandato da ex-presidente Dilma Rousseff, contra 20 (vinte) votos contrários à cassação (BRASIL, 2016e), entendeu-se que a Comandante Máxima do Estado cometeu os delitos de Responsabilidade.

Em votação subsequente, o Senado Federal decidiu por afastar a condenação à inabilitação para exercício de cargo público, em razão de não se ter obtido o quórum de 2/3 (dois terços) dos senadores em votação necessária. Encerrou-se, assim, o referido processo, afastando-se do cargo de Presidente a Sra. Dilma Rousseff.

\subsection{A denúncia contra o Presidente Michel Temer pela prática do crime de corrupção}

No dia 18 de maio de 2017, o Supremo Tribunal Federal (STF) havia divulgado áudios onde o empresário Joesley Batista, um dos controladores do grupo J\&F, estaria dialogando com o então presidente da República Michel Temer. Segundo a conversa (REVISTA EXAME, 2017), o empresário fala sobre propina a um procurador da República, a manipulação de dois juízes federais e o pagamento de vantagens indevidas ao exparlamentar Eduardo Cunha.

Ao tomar conhecimento da situação e posse das provas, o Procurador-Geral da República formulou denúncia contra o presidente da República pela prática de corrupção passiva, pois teria recebido, direta ou indiretamente, a quantia de $\mathrm{R} \$ 500.000,00$ (quinhentos mil reais), por intermédio de um deputado federal, também denunciado (MINISTÉRIO PÚBLICO FEDERAL, 2017).

A denúncia foi submetida à Câmara dos Deputados, que foi recebida pelo presidente da Câmara, e determinou a entrega de cópias aos demais deputados e determinou a instauração de Comissão para avaliação da denúncia e formulação do parecer para votação.

$\mathrm{Na}$ Comissão de Constituição e Justiça, o relator do (primeiro) parecer, o Deputado Sergio Zveiter, elaborou parecer favorável à aceitação da denúncia, em virtude dos fortes indícios que havia contra o presidente da República (inclusive o áudio anteriormente citado). Neste sentido, instantes antes da leitura do parecer, os partidos da base aliada do 
Governo trocaram os seus representantes na Comissão, a fim de rejeitar o parecer pela aceitação da denúncia.

Em seguida, houve elaboração de um novo parecer (segundo), pelo parlamentar Paulo Abi-Ackel, indo em sentido contrário ao primeiro parecer, alegando que a denúncia contra o presidente Michel Temer seria infundada, que não havia provas suficientes, e que a abertura de um novo processo de impedimento lançaria o Brasil em uma "profunda crise".

Nesse sentido, o parecer do deputado Paulo Abi-Ackel foi levado ao Plenário da Câmara dos Deputados, e foi colocado em votação, onde a maioria dos membros da Casa votaram a favor do parecer - 263 (duzentos e sessenta e três) votos (contra a investigação de Michel Temer) e 227 (duzentos e vinte e sete) votos contra o parecer (a favor da investigação).

A maioria dos argumentos utilizados pelos congressistas para barrarem as investigações contra o Presidente são ancorados no fato de que o Brasil estaria em uma grave recessão e profunda crise política, e que o país não resistiria a mais uma abertura de processo de impedimento contra o Chefe do Executivo.

Assim sendo, a denúncia contra o Presidente da República fica suspensa até o término do seu mandato, onde pode haver a continuidade das investigações e o processo tramitará na Justiça ordinária pela prática de crime comum.

\subsection{Uma (breve) análise do panorama jurídico-político dos casos Dilma e Temer}

As acusações feitas contra a ex-presidente da República Dilma Rousseff eram comumente chamadas de "conjunto da obra", tendo em vista que houve grande exercício retórico e utilização de argumentos políticos e morais para a construção das acusações. Em virtude do "conjunto da obra", houve a condenação e a perda do mandato da Representante do Executivo, agravando-se ainda mais a crise política que antes havia.

Após a liberação dos citados áudios, houve apresentação de denúncia contra o Presidente Temer pelo crime de corrupção. Dias antes de ser votada a denúncia contra o então Presidente, o Governo Federal anunciou a liberação de emendas parlamentares (destino de verbas para os redutos eleitorais dos deputados). Os valores liberados foram 
cerca de $\mathrm{R} \$ \mathbf{7 6 8 . 0 0 0 . 0 0 0 , 0 0}$ (setecentos e sessenta e oito milhões de reais) no mês de maio/2017; R\$ 1.600.000.000,00 (um bilhão e seiscentos milhões de reais) no mês de junho (mês em que o Presidente foi denunciado) e $\mathrm{R} \$$ 1.900.000.000,00 (um bilhão e novecentos milhões de reais) no mês de julho (MARIANI; TAKAHASHI, 2017).

Ao analisar sistemicamente as situações, cabe salientar que Direito não é economia, nem política e nem educação, não produz obras de arte nem cura enfermidades (LUHMANN, 2005, p. 72). Para que o sistema tome decisões, é necessário levar em conta dois aspectos: (i) as programações condicionais e (ii) os códigos binários.

Os códigos binários são esquemas específicos de distinção que é caracterizado por um rígido binarismo com a exclusão de terceiros valores. Este binarismo vai se expressar na lógica no princípio do terceiro excluído, onde, por exemplo, uma comunicação científica é verdadeira ou não é verdadeira, não podendo ser "meio verdadeira". O código binário é característico pela drástica redução de uma gama infinita de possibilidades a duas opções relacionadas mediante uma negação (CORSI; ESPOSITO; BARALDI, 1996, p. 40-41).

Luhmann (2005, p. 74) assevera que o código binário do direito (direito/não direito, ou legal/ilegal) tem importância decisiva para a diferenciação do sistema jurídico, posto que o dota com uma forma de lidar com a contingência. Portanto, tudo aquilo que existe dentro da esfera de relevância jurídica pode ser legal ou ilegal. E tudo aquilo que não se encaixe dentro deste código só terá relevância jurídica se for uma questão preliminar importante às decisões sobre justiça ou injustiça.

Já os programas condicionais, guardam estrita relação com os procedimentos que ocorrem dentro do sistema, bem como a forma de decisão. É característico que as sociedades modernas apresentem uma positivação do direito - e a dimensão material desta positivação diz respeito aos programas de decisão.

Na perspectiva luhmanniana, o conceito de programação significa que os problemas podem ser definidos especificando-se as condições restritivas de suas soluções, e que eles podem ser resolvidos através de decisões baseadas nessa definição. Um dos momentos de positivação do direito é a sua reestruturação na forma de programas decisórios (LUHMANN, 1985, p. 27). 
Portanto, é necessário que se fixe condições para que as decisões sejam consideradas corretas, assim vinculando-se a uma tendência de condicionamento das normas jurídicas. Dessa forma, não quer se dizer que a expressão seja na necessária formulação de princípios jurídicos, mas sim na utilização através de decisões. Ou seja, se forem preenchidas determinadas condições (conjunto de fatos previamente definidos), deve-se adotar determinada decisão (LUHMANN, 1985, p. 28).

Assim sendo, qualquer fato que ingresse no sistema jurídico, deverá obedecer ao código diferença legal/ilegal e seguir os programas de decisão jurídicos. Portanto, ambos os julgamentos da ex-presidente Dilma e do presidente Temer deveriam seguir os critérios jurídicos - embora julgados por membros do Congresso Nacional.

Os parlamentares da Câmara dos Deputados e do Senado Federal, ao se tornarem julgadores de uma demanda jurídica, tornaram-se juízes de uma causa, devendo obedecer aos programas, critérios e código jurídico.

A figura do juiz, na concepção luhmanniana, não tem porque valorar ou calcular as consequências da aplicação de um programa condicional. A única margem de cálculo das consequências que o juiz pode fazer são aquelas que se reduzem à interpretação da norma (do programa). Tendo em vista que a complexidade das cadeias de consequências são enormes, uma decisão judicial não pode ser fundamentada com base nelas (ALCOVER, 1993, p. 279).

Ao julgarem o processo de impedimento da ex-presidente Dilma Rousseff, os congressistas utilizaram-se de programas e códigos político, moral e econômico, além de justificarem suas decisões com base na cadeia de consequências que a permanência no poder da ex-presidente causaria ao panorama social, ao invés de decidirem com base na própria existência do programa jurídico de decisão.

No julgamento da denúncia contra o atual presidente, Michel Temer, os congressistas se valeram dos programas e códigos econômico e político, também justificando suas decisões suas com base na cadeia de (supostas) consequências que aconteceriam no caso de abertura de novo processo de impeachment.

Caso os congressistas decidissem em conformidade com as estruturas sistêmicas jurídicas, deveriam verificar a conduta de cada um dos denunciados e então analisar se 
estão de acordo com as normas positivadas, proferindo a decisão baseada na própria existência do código, ou seja, dizendo se a conduta é legal ou ilegal, para só então demandar ao sistema político para utilizar da força e impor as sanções necessárias.

Através destes dois casos, que envolveram três grandes subsistemas sociais (econômico, jurídico e político); dois grandes meios de comunicação simbolicamente generalizados (o poder/direito e o dinheiro) e um grande acoplamento estrutural (a Constituição), há fortes indícios que no Estado Brasileiro não existe uma completa diferenciação funcional sistêmica, onde os julgadores de certas demandas acabam utilizando elementos do ambiente para orientar suas decisões, fazendo com que o sistema do Direito passe a se reproduzir com elementos estranhos à estrutura jurídica.

\section{CONCLUSÃO}

Por tudo exposto, verificou-se que a hipótese de pesquisa levantada no início deste trabalho foi satisfeita, ou seja, hoje, no Brasil, é possível dizer que o sistema do Direito não é completamente autônomo e não se diferencia funcionalmente de forma completa dos demais sistemas ao seu redor - quer dizer, o Direito sofre de insuficiência de diferenciação funcional.

Tal insuficiência ocorre por que em determinados casos os meios simbolicamente generalizados do Poder e do Dinheiro acabam por influenciar os agentes do sistema jurídico, fazendo assim com que não mais se reproduza autopoieticamente, mas sim com base em vínculos políticos, vantagens econômicas, ligações pessoais, entre outros.

Diante desta insuficiência de diferenciação funcional, o Direito deixaria de operar com seus próprios códigos e processos e passaria a decidir com base em elementos políticos e econômicos. O Direito deixaria de buscar sua justificação no próprio Direito para buscar em elementos externos, quer dizer, as decisões seriam lícito porque aliado, lícito porque tem dinheiro...

A condenação da ex-presidente Dilma Rousseff foi justificada, fortemente, por elementos políticos, bem como razões econômicas, muito embora os elementos jurídicos da acusação fossem extremamente frágeis. Já no que tange à denúncia por corrupção contra o presidente Michel Temer, os elementos acusatórios eram juridicamente muito 
mais coesos que no caso da ex-presidente, no entanto, os congressistas decidiram por suspender a denúncia sob as alegações de que o país não superaria as consequências políticas e econômicas.

Ou seja, naquele caso, utilizou-se de elementos políticos e econômicos para justificar uma transgressão a expectativas normativas, enquanto neste último os elementos políticos e econômicos justificaram a suspensão da denúncia contra o presidente. Independentemente de juízos de valor sobre ambas as situações analisadas, as decisões deveriam ter sido tomadas com base nos critérios, programas e código do sistema jurídico.

Tendo em vista que os sistemas sociais são autopoieticos, quer dizer, só podem se (re)produzir a partir de seus elementos, as decisões nos dois casos deveriam ter sido tomadas conforme os elementos jurídicos. Percebendo que os elementos de justificação utilizados são estranhos ao sistema do Direito, é possível identificar que no Brasil não existe uma completa diferenciação funcional do sistema do Direito.

\section{$\square \square \square$}

\section{REFERÊNCIAS}

ALCOVER, Pilar Giménez. El Derecho en la teoría de la sociedad de Niklas Luhmann. Barcelona: José Ma Bosch Editor, 1993.

BECHMANN, Gotthard; STEHR, Nico. Niklas Luhmann. Tempo Social. Rev. Sociol. USP, S. Paulo, v. 13, n. 2, p. 185-200, nov. 2001.

BICUDO, Hélio; PASCHOAL, Janaína C. Denúncia por Crime de Responsabilidade. 2015. Disponível em: <http://www.migalhas.com.br/arquivos/2015/9/art20150901-04.pdf>. Acesso em: 27 jan. 2018.

BRASIL. Lei 1.079, de Abril de 1950. Define os crimes de responsabilidade e regula o respectivo processo de julgamento. Brasília, DF: Diário Oficial da União, 1950. Disponível em: <www.planalto.gov.br/ccivil_03/leis/L1079.htm>. Acesso em: 27 jan. 2018.

BRASIL. Constituição (1988). Constituição da República Federativa do Brasil. Brasília, DF: Senado Federal, 1988.

BRASIL. Comissão Especial Destinada a dar Parecer sobre a Denúncia... Denúncia por Crime de Responsabilidade no 1, de 2015. Brasília: Câmara dos Deputados. Disponível em:

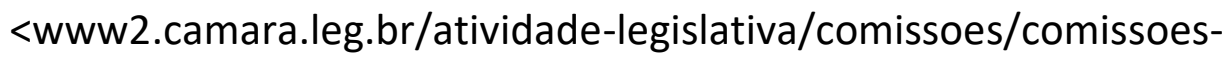
temporarias/especiais/55a-legislatura/denuncia-contra-a-presidente-da- 
republica/documentos/outros-documentos/ParecerdoRelatorResumo.pdf>. Acesso em: 29 jan. 2018.

BRASIL. Comissão Especial de Impeachment. Parecer no, de 2016, referente à admissibilidade da DEN no 1, de 2016 [DCR no 1, de 2015, na origem]. 2016a. Brasília: Senado Federal. Disponível em: <www.senado.leg.br/atividade/rotinas/ materia/getPDF.asp?t=192353\&tp=1>. Acesso em: 29 jan. 2018.

BRASIL. Comissão Especial de Impeachment. Resposta à acusação apresentada à Comissão Especial de Impeachment, pela Defesa da ex-presidente Dilma Rousseff. 2016b. Brasília: Senado Federal. Disponível em: $<w w w . s e n a d o . l e g . b r / a t i v i d a d e / r o t i n a s / m a t e r i a / g e t P D F . a s p ? t=194290 \& t p=1>$. Acesso em: 30 jan. 2018.

BRASIL. Comissão Especial de Impeachment. Alegações finais pelos denunciantes, no processo de Impeachment da ex-presidente Dilma Rousseff. 2016c. Brasília: Senado Federal. Disponível em: <www.senado.leg.br/atividade/rotinas/materia/ getPDF.asp?t=198410\&tp=1>. Acesso em: 30 jan. 2018.

BRASIL. Comissão Especial de Impeachment. Alegações finais pela defesa, no processo de Impeachment da ex-presidente Dilma Rousseff. 2016d. Brasília: Senado Federal. Disponível em: <www.senado.leg.br/atividade/rotinas/materia/getPDF.asp? $\mathrm{t}=198410 \& \mathrm{tp}=1>$. Acesso em: 30 jan. 2018.

BRASIL. Comissão Especial de Impeachment. Sentença do Processo de Impeachment da ex-presidente Dilma Rousseff. 2016e. Brasília: Senado Federal. Disponível em: $<$ www12.senado.leg.br/noticias/arquivos/2016/08/31/veja-a-sentenca-de-impeachmentcontra-dilma-rousseff>. Acesso em: 30 jan. 2018.

CANOTILHO, J. J. Gomes. "Brancosos" e Interconstitucionalidade: Itinerários dos Discursos sobre a Historicidade Constitucional. 2nd. ed. reimp. Coimbra: Editora Almedina, 2012.

CLAM, Jean. What does it imply to operate on the basis of difference instead of identity? Towards a post-ontological theory of society. In: NIELS LEHMANN, Lars Qvortrup; WALTHER, Bo Kampmann (Eds.). The Concept of the Network Society: Post-Ontological Reflections. Copenhagen: Samfundslitteratur Press, 2007.

CORSI, Giancarlo, ESPOSITO, Elena; BARALDI, Claudio. GLU: glosario sobre la teoria social de Niklas Luhmann. Traducción de Miguel Romero Pérez, Carlos Villalobos; bajo la dirección de Javier Torres Nafarrate. Ciudad de Mexico: Universidad Iberoamericana, 1996.

DIREITO UFPR. Teoria Sistêmica com Raffaele De Giorgi - Aula 02. Palestra [22 de julho de 2014]. Tempo de duração: $72 \mathrm{~m}$ 44s. Curitiba: Faculdade de Direito da UFPR. Disponível em: <https://www.youtube.com/watch?v=9wjybeqiuPM\&t=1184s>. Acesso em: 30 jan. 2018.

LUHMANN, Niklas. Sociologia do Direito I. Tradução de Gustavo Bayer. Rio de Janeiro: Edições Tempo Brasileiro, 1983.

LUHMANN, Niklas. Sociologia do Direito II. Tradução: Gustavo Bayer. Rio de Janeiro: Edições Tempo Brasileiro, 1985. 
LUHMANN, Niklas. Ecological Communication. Translated by John Bednarz, Jr. Chicago: University of Chicago Press, 1989.

LUHMANN, Niklas. El derecho como sistema social. In: DIEZ, Carlos Cómez-Jara (Ed.). Teoría de sistemas y derecho penal: fundamentos y posibilidades de aplicación. Granada: Comares, 2005.

LUHMANN, Niklas. La Sociedad de la Sociedad. Traducción: Javier Torres Nafarrate. Ciudad de México: Editorial Herder, 2006.

LUHMANN, Niklas. Sistemas Sociais: esboço de uma teoria geral. Tradução de Antonio C. Luz Costa, Roberto Dutra Torres Junior, Marco Antonio dos Santos Casanova. Petrópolis: Vozes, 2016a.

LUHMANN, Niklas. O Direito da Sociedade. Tradução Saulo Krieger. São Paulo: Martins Fontes, 2016b.

MARIANI, D.; TAKAHASHI, F. Emendas parlamentares anteriores à votação beneficiam governo e oposição. Folha de São Paulo, 2017. Disponível em: <http://www1.folha.uol.com.br/poder/2017/08/1907018-emendas-parlamentaresanteriores-a-votacao-beneficiam-governo-e-oposicao.shtml>. Acesso em: 30 jan. 2018.

MATURANA, Humberto R.; VARELA, Francisco J. Autopoiesis and cognition: the realization of the living. Dordrecht: D. Reidel Publishing, 1980.

MINISTÉRIO PÚBLICO FEDERAL. Denúncia pelo Crime de Corrupção Passiva. Brasília: Procuradoria-Geral da República. 2017. Disponível em: $<$ www.mpf.mp.br/pgr/documentos/inq-4483-cota-denunciatemer.pdf/at_download/file>. Acesso em: 31 jan. 2018.

NEVES, Marcelo. A Constitucionalização Simbólica. São Paulo: Editora Acadêmica, 1994.

NEVES, Marcelo. De la autopoiesis a la alopoiesis del Derecho. Doxa, Alicante, v. 19, p. 403420, 1996a.

NEVES, Marcelo. Constitucionalização Simbólica e Desconstitucionalização Fática: Mudança Simbólica de Constituição e Permanência das Estruturas Reais de Poder. Revista de Informação Legislativa, Brasília, v. 33, n. 132, p. 321-30, 1996b.

NEVES, Marcelo. Between Under-Integration and Over-integration: Not Taking Citizenship Seriously. In: SOUZA, Jessé; SINDER, Valter (Ed.). Imagining Brazil. Lanham: Lexington Books, 2005.

NEVES, Marcelo. Os Estados no centro e os Estados na Periferia: alguns problemas com a concepção de Estados da Sociedade mundial em Niklas Luhmann. Revista de Informação Legislativa, v. 206, p. 111-36, 2015.

REVISTA Exame. Conversa entre Joesley Batista e Michel Temer. DIsponível em: <https://soundcloud.com/user-798211168/conversa-entre-joesley-batista-e-micheltemer>. Acesso em: 31 jan. 2018.

ROCHA, Leonel Severo; SCHWARTZ, Germano; Clam, Jean. Introdução à teoria do sistema autopoiético do Direito. 2. ed., rev. e ampl. Porto Alegre: Livraria do Advogado, 2013. 
SCHWARTZ, Germano. As teses radicais de Luhmann. Revista de Estudos Constitucionais, Hermenêutica e Teoria do Direito (RECHTD), v. 6, n. 1, p. 111-114, jan./jun. 2014.

SOUZA, Matheus Figueiredo Nunes de; TONET, Fernando. A insuficiência de diferenciação funcional observada a partir da crise no cenário brasileiro. RBSD - Revista Brasileira de Sociologia do Direito, v. 5, n. 3, p. 180-202, set./dez. 2018.

Recebido em: 07/05/2018

Aprovado em: 07/08/2018 